\title{
How Research Skills Affect Indonesian Postgraduate Students Writing Outcomes: Publication Review
}

\author{
Sudarmo', Lusy Tunik Muharlisiani ${ }^{2}$, Sardjana Orba Manullang3, Erwinsyah Satria ${ }^{4}$, \\ Yeasy Agustina Sari ${ }^{5}$ \\ 1 Sekolah Tinggi Ilmu Ekonomi Balikpapan, Indonesia \\ 2 Universitas Wijaya Kusuma Surabaya, Indonesia \\ 3 Universitas Krisnadwipayana, Indonesia \\ 4 Universitas Bung Hatta, Indonesia \\ ${ }^{5}$ Institut Agama Islam Negeri (IAIN) Metro Lampung, Indonesia
}

lusytm_fbs@uwks.ac.id

\begin{tabular}{|c|c|}
\hline \multirow{3}{*}{$\begin{array}{l}\text { ARTICLE INFO } \\
\text { Article history: } \\
\text { Received } \\
\text { February 08, } 2021 \\
\text { Revised } \\
\text { June 04, } 2021 \\
\text { Accepted } \\
\text { June 23, } 2021\end{array}$} & ABSTRACT \\
\hline & $\begin{array}{l}\text { This research reviewed how research skills affect the writing results of } \\
\text { Indonesian postgraduate students. As academics have understood it. the } \\
\text { success of studying at the postgraduate level was closely related to the } \\
\text { skills and abilities to research various content and contexts of the field of } \\
\text { study. The researchers have conducted a data collection series consisting } \\
\text { of literature searching, observation, and documentation to prove this } \\
\text { assumption. Furthermore, data was analyzed by defining the research } \\
\text { question, collecting answers by sharpening the correlation and } \\
\text { comparison between the questions and answers or findings. Finally, the } \\
\text { researchers interpret in-depth whether the findings were valid and } \\
\text { reliable. The design used phenomenology approach. Considering the } \\
\text { data and the analysis results, the researchers conclude that the skills and } \\
\text { abilities to research Indonesian postgraduate students greatly influence } \\
\text { each writing or lecture assessment's quality or outcome, including } \\
\text { research activities, final semester assignments, and weekly assignments. } \\
\text { Therefore, the findings have a meaningful input for postgraduate } \\
\text { students and policymakers for studying in master and undergraduate } \\
\text { programs in Indonesia. }\end{array}$ \\
\hline & Keywords: Research Skills, Writing Outcomes, Academic Study Review \\
\hline ant & $\begin{array}{l}\text { Sudarmo., et. al. (2021). How Research Skills Affect Indonesian Postgraduate } \\
\text { Students Writing Outcomes: Publication Review. Jurnal Iqra': Kajian Ilmu } \\
\text { Pendidikan, 6(1). 225-234. https://doi.org/10.25217/ji.v6i1.1406 }\end{array}$ \\
\hline his is & by-sa/4.0/ \\
\hline
\end{tabular}

\section{INTRODUCTION}

Proficiency in research is one of the academic skills that every student must possess, especially those studying at the postgraduate level. (Terraschke \& Wahid, 2011; Wingate, 2015; Arnó-Macià \& Mancho-Barés, 2015; Rachmawati et al., 2020). It is because a typical study and activity of completing postgraduate coursework involve research and publication activities. For the quality of lectures and completion of coursework to produce high scores, students and lecturers must have the ability to do research based on course objectives and publication-based studies for the marking and graduation purposes process. Mastering quality research skills, of course, students and lecturers start from mastering research skills. These skills are beneficial in being able to 
produce high-quality writing starting from collecting data, analyzing information from various data sources, searching for data online, criticizing data, organizing and reviewing it, interpreting, and being able to develop a new understanding of a field of science in the field of higher education. And other research institutions. Based on these skills, the researchers examind students' abilities and research skills in postgraduate programs and their impact on the quality of writing results through publications that discuss the relationship between the two variables above.

The author's experience during college in the postgraduate program and since becoming a lecturer who is given the task of guiding and testing students who are banned from doing research on final semester assignments and completing studies, both lecturers and students experience many problems when dealing with student guidance assignments starting from submitting study plans. The research proposal reaches the stage of implementing and reporting the study results and submits a thesis defend trial examination. The most pronounced obstacle is the impact of the students' inability to face the stages of the task process, which are directly related to the need for their studies to spend a long time completing lectures and obtaining a bachelor's degree with very unsatisfactory quality. Belland, (2009) also said that academic achievement is the impact of students' research ability to improve the learning experiences of overseas postgraduate participants in Australia.

Eagan Jr et al., (2013) suggested that postgraduate students' research good mastery program shows a positive influence on subsequent student participation in professional education programs and vocational careers after graduation. (Hur \& Suh, 2012; Nickel, 1987; Auchincloss et al., 2014). However, these postgraduate studies generally focus on research mastery and skill for students of one study program, pure science only then the program coordinator reluctant to set the program that improves research for the learning goal. This project is an attempt was made to analyze student research skills carried out on research programs from many different individual students, namely students who learn course content and those who practice English course education. Research models for students from Biology programs are usually based on laboratory or fieldwork. In contrast, research models for students from English language education courses are usually based on their learning process in daily communication practices.

As a collection of all postgraduate learning experiences, both in work assignments and writing research reports, this is empirical evidence that student achievement in writing skills during their education is primarily determined by mastery of research skills. Through applying these research skills, postgraduate students are directed to develop and continue to hone new knowledge in their fields of expertise in line with research skills gradually and regularly. Later, new knowledge will be formed in the realm of research skills built indirectly that show students' talents and interest in the specific research skills developed during postgraduate education. In this case, of course, all application research experts can monitor students' development towards research skills so that students do not feel reluctant to work with the research skills they find at the next level of education. It follows the status attainment theory or can be interpreted as the proposed status attainment theory.

As stated in the beginning, this study aims to understand how research skills impact Indonesian postgraduate students, especially efforts to improve writing learning skills. So, one way to know about this impact is by reviewing the published results of experts in related fields. Suppose the researchers keep away from the typical content and challenges of postgraduate study anywhere in the world. In that case, the 
answer is that the postgraduate course is very much tied to the potential and mastery of research skills were; through these skills; postgraduate students will easily face and complete all assignments oriented towards the final product, in the form of academic writing. In addition, talking about academic writing means talking about research skills, which includes many other skills. Examples of skills in searching for data, analyzing, managing, and communicating both in writing and verbal presentations are the main reason. So all activities involved in writing are primarily determined by research skills. We consider this study very urgent to be carried out Hart, (2004).

It was further explained that what is meant by these characteristics, one of which is the achievement of previous individual academic achievements. This theory is a useful point of view to understand the factors influencing a person's intention to continue to higher education. Several research results indicate that the measure of academic achievement achieved by a person, such as the academic achievement index of bachelor program, is a significant predictor of their ability to attend education at a more advanced level. (Pascarella et al., 2004; Kuh et al., 2006; Tinto, 2012). Through mapping students' difficulties in carrying out this thesis, it is hoped that an alternative thesis guidance program can be designed that focuses on the root of the problems faced by students. It is essential because it will impact the accreditation of study programs and the research experience possessed by students, which can have implications for the next education that the student will take.

\section{METHODS}

This paper analyzed the relationship between Indonesian postgraduate students' research skills and the quality of writing skills for course evaluation and journal publication from a review of previous studies. Such as the consideration of research experts and their relation to writing productivity that the most crucial factor of success towards good quality writing and sustainability to enter the career world later is the readiness of prospective master and doctoral program students with the development of superior research skills and other factors possessed by students alone. To the analysis of the above problem studies, a series of information collection has been carried out. Including critical reviews on international journal publications discuss various activities to strengthen research skills that impact writing skills in postgraduate programs that only seek college success in the form of high scoring and career advancement that has sustainable value in the future where the graduate is located. After the data is collected, the analysis process starts with determining the research question. The researchers searched the study's theme with keywords to obtain information, evaluate critically, synthesize data, identify themes, determine organizational formats, and format reports with ethical considerations and the relevance of information findings. In-depth analysis to critically looking for validity and reliability so that these findings are relevant to the paper's theme formulation has become the concern. The design and method of data analysis were carried out under the phenomenological approach's guidance. (Tattersall et al., 2011; Beest et al., 2009; Berg, 2001); Bhowon \& Bundhoo, 2016).

\section{RESULT AND DISCUSSION}

As mentioned above, this research was carried out to understand the effectiveness of the mastery of research skills by Indonesian postgraduate students on the quality of writing results during college and when they enter tenure both as academics and other professionals in industries that require expertise in completing 
work that is full of research components and critical thinking. Therefore, in the reporting section of this study, the researchers present the results of a review of several international publications that have proven that research skills are closely related to the achievements of the world of writing, such as journal projects and other academic works. Reason means of practice, through this postgraduate research program, students are expected to have basic research knowledge and skills; in this case, biology research and writing in education research. Therefore, as required, the students must have the correct research knowledge and skills to avoid researchers' mistakes. Attention to this is increasing, along with the frequent errors found in several published research results. (Leonard et al., 2006; Morley, 2013). It's no secret that researchers who have published their research results are not free from mistakes.

As previously stated by Leonard, mistakes and even errors are often accrued, namely: published research results are a biased part of the research, data analysis, and reporting are often biased, in some areas of study it is often not replicated so that the resulting conclusions become inappropriate. Researchers such as students at the postgraduate level must further argue that they must make substantive changes in carrying out their research, minimize bias when conducting data analysis, and avoid unnecessary research errors. Therefore, with the knowledge of student difficulties when participating in this career. As said by experts, the solution is developing and improving research skills with different concepts and approaches before they depart to the next working career both during the study and life job opportunities in the fieldwork research program; it is hoped that improvements can be made to improve the knowledge and research skills of these prospective researchers.

Ali et al., (2019) found in the postgraduate supervision period that they explored the Postgraduate participant program's real-life learning time. These exciting things found in their study that those who came from weak research university background programs had a relatively poor perception of the power of research skill in working on course work in their postgraduate program. The most significant difficulty for them was the research skill implementation $(71.42 \%)$, followed by the reporting or writing quality issue $(60 \%)$. Finally, the publication matter $(77.14 . \%)$ means that most students were hard to pass their papers published in high-impact journals, mostly international ones. It is known from the number of items of research skills that are perceived as having challenging and challenging categories by research subjects from the two study programs in this study. Of course, this needs attention, especially from research mentors or course programs to anticipate in the early phase. Attention from the beginning of the research phase should be done because if the mentor can ensure that students understand what they are planning, difficulties in the next research stage can be avoided.

Still, most postgraduate students face difficulties and obstacles when working on coursework that involves more writing and research skills. Srinivasan et al., (2014) findings can be strong evidence that most postgraduate students in Indonesia do during their postgraduate studies. Srinivasan examines students' backgrounds with large workloads of full research skills and the barriers that make it difficult for them to submit published papers among postgraduate medical programs in India, showing real weaknesses at an early stage. They see this difficulty as a result of errors in providing research skills or working on the writing stage, and the results of research writing obtained are of no value. They are sufficient reasons to be rejected by the journal. This shows that students can apply research skills and produce high writing scores when students have planned early. The critical process of developing research

\section{8}


results of Srinivasan's research indicates that postgraduate students' research subjects about the difficulties at the planning stage of this study are quite diverse. Ideally, students should understand the research planning process related both theoretically and practically. Instructors need to ensure that students they mentor have the correct research skills. Research skills necessary to craft a good research proposal.

The skills was to plan research ideas, the skills to design research designs, the skills to formulate operational definitions. Definition of terms, skills in determining population \& research samples, skills in planning data analysis \& processing, and presenting proposals. In this case, the Cooksey \& McDonald, (2019) has proven that students can survive and be successful in research after postgraduate assignments if they are properly equipped with a range of research skills when working on assignments and writing final year-end papers. Likewise, Linn et al., (2015) have examined undergraduate research students' experiences with all the impacts and difficulties during the writing process for their final lecture. Their writing assignment experience has proven how important an opportunity is to strengthen opportunities to understand and practice all research skills. The experience of the two studies above notes that postgraduate students are directed to have authentic research experiences according to their fields of expertise through research in this postgraduate program. Students should not experience difficulties at the planning stage of this research and be skilled in formulating problems. The focus of research studies that must be carried out follows the skills that have been learned. Good theoretical knowledge about their area of expertise will make it easier for students to identify existing problems.

The students have difficulty identifying problems in authentic settings. The postgraduate supervisor and coordinator's job is to direct students to use this theoretical knowledge to identify authentic settings problems. Biology students find these items very difficult and are considered very easy by students of postgraduate programs. Many studies have discussed identifying and labeling research variables, formulate hypotheses, and determine the population \& research samples and design the research schedule. This shows that research subjects from biology study programs have lower self-confidence than research subjects from postgraduate education study programs. The implementation of research based on the findings shows a similarity in the research subjects' perceptions of research skills when conducting research. Research subjects argue that some research skills are quite difficult, especially research skills that expect instant completion. The research subjects responded well. This is related to supervisors and related parties' seriousness and the skills to manipulate \& control variables, collect data accurately, use time data collection efficiently, and effectively carry out research procedures. At the implementation stage, it can be seen that only scaling responses but with categories that tend to be the same.

At the implementation stage of this research, the skills that are felt to be prepared to deal with problems practically are the self-preparation of postgraduate students to avoid difficulties at the planning stage or proposal preparation adequately. For example, skills that are felt are difficult for skill items to identify problems, collect data accurately and report to write by following a supervisor guide or journal instructions if the purpose of writing is for publication. Research subjects need not feel difficult if the data collection instruments used have been adequately prepared at the planning stage, and data collection replication has been considered. In line with this, At the implementation stage of this research, the skills that are felt to be prepared to deal with problems practically are the self-preparation of postgraduate students to avoid difficulties at the planning stage or proposal preparation adequately. For example, 
skills that are felt are difficult for skill items to identify problems, collect data accurately and report to write by following a supervisor guide or journal instructions if the purpose of writing is for publication. Research subjects need not feel difficult if the data collection instruments used have been adequately prepared at the planning stage, and data collection replication has been considered.

In line with this, Cooper, (2004) wrote about postgraduate work experiences involving research papers under supervision to choose critical reviews of higher education programs' latest practices. These findings indicate that the stages of research implementation at postgraduate and research education are perceived as problematic by research subjects if supervisors' presence is insufficient (Anderson\& Bilorusky, J. A. 2021). There needs to be assistants' attention, reviewing the previous research planning process, and directly verifying the causes of difficulties in carrying out research. Especially in biology education research, its unique characteristics cause certain things to be considered. An example relates to physical education research, which is different from other scientific research objects full of science. The problems faced are complex; This is a challenge for research subjects. Their supervisors wrote about postgraduate work experiences involving research papers under supervision to choose critical reviews of higher education programs' latest practices. These findings indicate that the stages of research implementation at postgraduate and research education are perceived as problematic by research subjects if supervisors' presence is insufficient. There needs to be assistants' attention, reviewing the previous research planning process, and directly verifying the causes of difficulties in carrying out research. Especially in education research, its unique characteristics cause certain things to be considered. An example relates to physical education research, which is different from other scientific research objects full of science. The problems faced are complex; This is a challenge for research subjects and their supervisors.

The findings presented earlier show that the skills needed by research subjects at the reporting or writing stage of research results occupy a severe level of difficulty after the research implementation stage. There are two possible causes for this condition. First, research subjects have the skills needed at the reporting stage, but because there are problems at the implementation stage, the research subjects have difficulty dealing with research data. The second possibility is that the research subject does not have sufficient skills for this reporting stage. Even if the research results are obtained correctly, the reporting stage becomes a problem. This item is considered fatal by the students of the respective study program and is considered easy. This item is concerned with presenting data in the appropriate difficulty stage, formulating conclusions, and formulating research abstracts.

Based on these data, the education study program's research subjects had better confidence in these items than research subjects from the biology study program. Whatever type of research is carried out, the researcher should report his research results as best as possible. Cumming \& Vismara, (2017) said writing the research results is related to research integrity issues. Furthermore, the research's integrity is shown by a researcher who reports the research he has done in a full, accurate, and reasonable standard of procedure. One more thing related to the research's integrity is the values and behaviors that the researchers have. The researcher's honesty and ethics can be shown by reporting the research results in their entirety and with reasonable accuracy. Use of scientific library sources based on the findings, it is known that there is a similar trend regarding the use of scientific literature sources in Biology study program students. 
The average publication visited show that research skill subjects had the same perception that this ability was included in the difficult category. The differences are only visible on the context category scale; Postgraduate students of certain subject education tend to have challenging perceptions. Other study program students have more challenging perceptions about using scientific literature sources in completing all assignments, including thesis writing. This happened because, among others, the habit of using literature from scientific sources in foreign languages is minimal. This happens because the students' low foreign language skills generally occur. Need additional support from mentors for this problem. Guidance of companions in reviewing relevant scientific journals is one activity that can be carried out to direct guidance students. (Linn dkk., 2015). Second, inadequate facilities make it difficult for research subjects to obtain suitable scientific literature for free. For this problem, the institution should take part in providing a solution. It is hoped that relevant scientific journals will be available through existing library institutions to be used as sources of literature. It would be great if the central government served borrowing books and was involved in directing the review process to students to be more focused. Third, the lack of habituation of using scientific literature sources in lectures makes research subjects difficult when faced with this problem.

Unlike the previous components, students of postgraduate education study programs have difficulty in the guidance process; This can be seen from the responses given to all research implementation stages. Meanwhile, undergraduate study program students feel there is no difficulty in the guidance process because the expected scope and level of study acuity are not too deep. This can be seen from the responses given when submitting proposals and session after supervisors' guidance. The difficulty is that there is only one thing when students maintain written works that undergraduate students consider difficult. This is related to conducting the research process independently. According to Linn et al., (2015) researching undergraduate programs requires a lot of effort, time, and money. The difficulties felt by research subjects from postgraduate study programs indicate that the supervisor's role is vital. They are needed to direct students to obtain content. The research process from beginning to end, including writing processes, so that students can easily take responsibility for all their tasks.

To write a postgraduate student's academic assignment, especially a thesis at the end of the school period, the faculty and the postgraduate program coordinator's responsibility needs to be reminded again. Likewise, the supervisor from the planning stage to the student reporting stage requires a careful stage process. Research results in the form of writing can be improved following the core competencies of postgraduate level programs. This is following the explanation put forward by Linn et al., (2015) that guidance activities can be carried out by involving students in scientific meetings in the same research field, reflecting on relevant scientific journals, and learning to synthesize their insights and include them in research proposals, research reports, or posters of research results. Technical factors can cause the existence of difficulties in the research subjects of the biology education course. In the same semester, research subjects attended a professional training program at school while conducting research. This resulted in limited time to carry out the coaching process. Besides, even mentors with their busy lives may not have the right time to mentor their students, which is a problem.

This study's contribution is the solution to problems in the class of graduate students related to the problem of expertise in research, and low-quality academic 
writing would be answered through voices from experts in the field of management and the graduate course system. The researchers understand that experts' results are field evidence from various contexts of international studies that will be very relevant for us to adopt for improving the quality of learning in postgraduate programs. Likewise, this study's results can be an essential input for postgraduate curriculum innovation in Indonesia, which has so far been proven to be unable to improve the quality of written academic skills. The limitation of this study rely on secondary data, namely data on scientific publication records of international journals. The limitation that we estimate is this secondary data, which is not so much in number but is expected to answer the complex and complicated problems faced by postgraduate circles in Indonesia. This review study's limitations are the method and sample selection section, where the data analysis procedure is straightforward, which requires interpretation to get answers to the questions of this study. Meanwhile, our sample selection only uses searching topics directly related to the problem theme, namely the effectiveness and usefulness of academic research for Indonesian postgraduate students-insufficient sample size where do not present statistical measurements. Another weakness is the lack of previous research studies on the topic to only rely on existing findings. Meanwhile, our access to data relies on data searching online. Because the researchers carried out this study during the pandemic, it was difficult for us to find field data, including time constraints due to the national policy on the response to COVID-19 with restrictions on public movement. Likewise, many conflicts arise from cultural bias and other personal issues that the researchers did not realize when reviewed this issue.

\section{CONCLUSION}

In this final section, it can briefly summarize that Indonesian postgraduate students' research skills and skills are strongly influenced by the seriousness of supervisors or postgraduate program coordinators to successfully carry out highquality writing assignments according to the department's expectations. Moreover, the postgraduate level, including the introduction and supervision of activities to strengthen research expertise, which includes working on final semester assignments and weekly assignments. Likewise, postgraduate students need to seriously develop several research skills starting from the stages of determining study problems, searching for data, analyzing data, writing high impact quality report reports such as expectations of postgraduate majors in Indonesia. Therefore, it is hoped that this study's findings can be a very contributive input for postgraduate students, supervisors in postgraduate programs, and policymakers to advance research programs at the university level, especially the postgraduate doctoral program where the research and writing components are urgently prioritized.

\section{ACKNOWLEDGEMENT}

The researchers are very grateful to the co-author himself for his excellent contribution, from the initial stages to the finalization phase of research work to writing. Likewise, for the university's assistance and consultation, especially our research flash light on behalf of the author, the researchers are very grateful that the paper entitled "How Research Skills Affect Indonesian Postgraduate Students Writing Outcomes: Publication Review" was completed on time. 


\section{AUTHOR CONTRIBUTION STATEMENT}

All authors have contributed equally in the process of completing this study from the initial stage to completion of the study with the study theme "How Research Skills Affect Indonesian Postgraduate Students Writing Outcomes: Publication Review."

\section{REFERENCES}

Ali, J., Ullah, H., \& Sanauddin, N. (2019). Postgraduate Research Supervision: Exploring the Lived Experience of Pakistani Postgraduate Students. FWU Journal of Social Sciences, 13(1). Google Scholar

Anderson, K., \& Bilorusky, J. A. (2021). Plans for a school-based project to involve students as teachers, learners, and colleagues of Artificial Intelligence. In Cases and Stories of Transformative Action Research (pp. 146-154). Routledge. Google Scholar

Arnó-Macià, E., \& Mancho-Barés, G. (2015). The role of content and language in content and language integrated learning (CLIL) at university: Challenges and implications for ESP. English for specific Purposes, 37, 63-73. https://doi.org/10.1016/j.esp.2014.06.007

Auchincloss, L. C., Laursen, S. L., Branchaw, J. L., Eagan, K., Graham, M., Hanauer, D. I., Lawrie, G., McLinn, C. M., Pelaez, N., \& Rowland, S. (2014). Assessment of course-based undergraduate research experiences: A meeting report. Am Soc Cell Biol. https:// doi.org/10.1187/cbe.14-01-0004

Beest, F. V., Braam, G. J. M., \& Boelens, S. (2009). Quality of Financial Reporting: Measuring qualitative characteristics. Google Scholar

Beitz, C. R. (2011). The idea of human rights. Oxford University Press. Google Scholar

Belland, B. R. (2009). Using the theory of habitus to move beyond the study of barriers to technology integration. Computers $\mathcal{E}$ Education, 52(2), 353-364. https:// doi.org/10.1016/j.compedu.2008.09.004

Berg, B. L. (2001). Qualitative Research Methods For The Social Sciences. ALLYN AND BACON. Google Scholar

Bhowon, U., \& Bundhoo, H. (2016). Perceptions and reasons for veiling: A qualitative study. Psychology and Developing Societies, 28(1), 29-49. https:// doi.org/10.1177\%2F0971333615622894

Cooksey, R. W., \& McDonald, G. (2019). Surviving and thriving in postgraduate research. Springer. Google Scholar

Cooper, T. C. (2004). How foreign language teachers in Georgia evaluate their professional preparation: A call for action. Foreign Language Annals, 37(1), 37-48. https:// doi.org/10.1111/j.1944-9720.2004.tb02171.x

Cumming, D. J., \& Vismara, S. (2017). De-segmenting research in entrepreneurial finance. Venture Capital, 19(1-2), 27.https:// doi.org/10.1080/13691066.2016.1225910

Eagan Jr, M. K., Hurtado, S., Chang, M. J., Garcia, G. A., Herrera, F. A., \& Garibay, J. C. (2013). Making a difference in science education: The impact of undergraduate research programs. American educational research journal, 50(4), 683713.https://doi.org/10.3102\%2F0002831213482038

Hart, C. (2004). Doing Your Masters Dissertation. SAGE. Google Scholar

Hur, J. W., \& Suh, S. (2012). Making learning active with interactive whiteboards, podcasts, and digital storytelling in ELL classrooms. Computers in the Schools, 29(4), 320-338.https:// doi.org/10.1080/07380569.2012.734275 
Kuh, G. D., Kinzie, J. L., Buckley, J. A., Bridges, B. K., \& Hayek, J. C. (2006). What matters to student success: A review of the literature (Vol. 8). Washington, DC: National Postsecondary Education Cooperative. Google Scholar.

Leonard, D., Metcalfe, J., Becker, R., \& Evans, J. (2006). Review of literature on the impact of working context and support on the postgraduate research student learning experience. New York, NY: The Higher Education Academy. Google Scholar

Linn, M. C., Palmer, E., Baranger, A., Gerard, E., \& Stone, E. (2015). Undergraduate research experiences: Impacts and opportunities. Science, 347(6222). Google Scholar

Morley, L. (2013). The rules of the game: Women and the leaderist turn in higher education. Gender and education, 25(1), 116131.https://doi.org/10.1080/09540253.2012.740888

Pascarella, E. T., Pierson, C. T., Wolniak, G. C., \& Terenzini, P. T. (2004). Firstgeneration college students: Additional evidence on college experiences and outcomes. The Journal of Higher Education, 75(3), 249284.https://doi.org/10.1080/00221546.2004.11772256

Rachmawati, M., Widjajanti, S., Ahmad, A., \& Aslan, A. (2020). The English Camps as Method of Promoting Fun English at Elementary School Level in Indonesia. Tapis: Jurnal Penelitian Ilmiah, 4(2), 174-182. https://doi.org/10.32332/tapis.v4i2.2563

Srinivasan, M., Poorni, S., Sujatha, G., \& Kumar, S. (2014). Research experiences, attitudes, and barriers to publishing among the dental postgraduate teachers: A cross-sectional study. Indian journal of dental research, 25(4), 454. Google Scholar

Tattersall, C., Powell, J., Stroud, J., \& Pringle, J. (2011). Mind mapping in qualitative research. Nursing times, 107(18), 20-22. Google Scholar

Terraschke, A., \& Wahid, R. (2011). The impact of EAP study on the academic experiences of international postgraduate students in Australia. Journal of English for Academic Purposes, 10(3), 173-182. https:/ / doi.org/10.1016/j.jeap.2011.05.003

Tinto, V. (2012). Completing college: Rethinking institutional action. University of Chicago Press. Google Scholar

Wingate, U. (2015). Academic literacy and student diversity: The case for inclusive practice. Multilingual matters. Google Scholar

\section{Copyright Holder :}

(c) Sudarmo, et al., (2021).

First Publication Right :

@ Jurnal Iqra' : Kajian Ilmu Pendidikan

This article is under: 